Revue de droit comparé du travail et de la sécurité sociale

3 | 2017

Le travail dans l'économie informelle, un défi pour le droit social

\title{
Réglementation de la sous-traitance dans le secteur privé
}

Patty Kalay Kisala

\section{CpenEdition}

Journals

Édition électronique

URL : https://journals.openedition.org/rdctss/411

DOI : $10.4000 /$ rdctss. 411

ISSN : 2262-9815

Éditeur

Centre de droit comparé du travail et de la sécurité sociale

Édition imprimée

Date de publication : 1 septembre 2017

Pagination : 160-161

ISSN : $2117-4350$

Référence électronique

Patty Kalay Kisala, "Réglementation de la sous-traitance dans le secteur privé », Revue de droit comparé du travail et de la sécurité sociale [En ligne], 3 | 2017, mis en ligne le 01 novembre 2017, consulté le 04 décembre 2021. URL : http://journals.openedition.org/rdctss/411 ; DOI : https://doi.org/ $10.4000 /$ rdctss. 411

\section{(c) $(1) \Theta \Theta$}

Revue de droit comparé du travail et de la sécurité sociale est mise à disposition selon les termes de la Licence Creative Commons Attribution - Pas d'Utilisation Commerciale - Pas de Modification 4.0 International. 


\section{PATTY KALAY KISALA Université Protestante au Congo}

\section{RÉGLEMENTATION DE LA SOUS-TRAITANCE DANS LE SECTEUR PRIVÉ}

Article 3 de la loi $n^{\circ} 17 / 001$ du 08 février 2017 fixant les règles applicables à la sous-traitance dans le secteur privé.

2 Sous-traitance de capacité : opération par laquelle l'entreprise principale fait appel temporairement à une autre société pour la réalisation d'une tâche ou la fabrication d'un produit qu'elle peut exécuter elle-même afin de faire face à des commandes supplémentaires(Article 3 de la loi $n^{\circ} 17 / 001$ du 08 février 2017 fixant les règles applicables à la soustraitance dans le secteur privé).

3 Sous-traitance de capacité et de spécialité : opération par laquelle l'entreprise principale recourt aux services d'une société spécialisée pour l'exécution d'une tâche requérant des équipements ou des compétences spécifiques dont elle ne dispose pas, aux fins de la réalisation de l'activité principale (Article 3 de la loi $n^{\circ} 17 / 001$ du 08 février 2017 fixant les règles applicables à la sous-traitance dans le secteur privél.

4 Sous-traitance de capacité et de marché : opération par laquelle une entreprise principale titulaire d'un marché recourt à une autre entreprise pour l'exécution de certaines obligations du contrat ou du marché (Article 3 de la loi $n^{\circ} 17 / 001$ du 08 février 2017 fixant les règles applicables à la sous-traitance dans le secteur privé).

5 Il faudra en fournir la preuve au Ministère compétent ou à l'autorité locale.

6 Avoir un registre de commerce et de crédit mobilier, une identification nationale et un numérod'impôt ; produire un document établissant qu'il est en règle avec l'administration fiscale ; présenter l'affiliation à un organisme de sécurité sociale. Toutefois, une formation médicale est éligible à la sous-traitance si elle est constituée conformément à la loi.
À travers la loi $n^{\circ} 17 / 001$ du 8 février 2017 fixant les règles applicables à la soustraitance dans le secteur privé, le législateur congolais a souhaité légiférer sur la soustraitance en raison de cas de pratiques abusives constatés ces dernières années ayant suscité de nombreux commentaires et questionnements. De prime abord, le législateur a défini le contrat de soustraitance ${ }^{1}$ et a identifié trois formes de soustraitance (sous-traitance de capacité2, soustraitance de capacité et de spécialité ${ }^{3}$, ou sous-traitance de capacité et de marché4] qu'on peut retrouver dans tous les secteurs d'activité et sur tout le territoire congolais, sauf dispositions légales régissant certains secteurs d'activité ou certaines professions.

Affirmant vouloir, par la voie de cette loi, soutenir les petites et moyennes entreprises (PME) à capitaux congolais d'une part et d'autre part protéger la main-d'œuvre nationale, le législateur congolais indique clairement que les activités de sous-traitance sont attribuées à des entreprises à capitaux congolais dont le siège social est situé sur le territoire national. Toutefois, en cas d'indisponibilité ou d'inaccessibilité avérée ${ }^{5}$ d'expertise congolaise, l'entrepreneur pourra recourir à tout autre entreprise de droit congolais ou à une entreprise étrangère pour autant que l'activité ne dépasse pas une durée de 6 mois.

Les entreprises souhaitant être éligibles pour se voir attribuer des activités de sous-traitance doivent répondre à certains critères prédéfinis ${ }^{6}$. Aussi, toute opération de sous-traitance se fait, en principe, à travers un appel d'offre. 
Les marchés de gré à gré sont autorisés lorsque le coût du marché est inférieur à cent millions de francs congolais? Les droits et obligations des différentes parties ainsi que les éléments du contrat de sous-traitance sont déterminés par la loi. Il n'est pas interdit au sous-traitant de soustraiter à son tour. Devant pareille situation, le sous-traitant de second rang est soumis aux mêmes conditions de forme et de fond que le sous-traitant originel. De même, deux ou plusieurs sous-traitants peuvent également co-traiter. En cas de co-traitance, chacun des co-contractants est tiers aux contrats passés par l'autre avec l'entrepreneur principal et est responsable de ses propres prestations.

Le législateur a tenu à spécifier que les entreprises sous-traitantes sont, au plan social, régies par la législation du travail. Il est bien clair que les relations entre le soustraitant et sa main-d'œuvre sont régies par la législation du travail. Le prêt illicite de main-d'œuvre ou le travail dissimulé sont interdits. Aussi, le législateur prohibet-il tout débauchage du personnel du sous-traitant par l'entrepreneur principal ou par le maître d'ouvrage. Ce choix du législateur, cherchant sans doute à préserver un certain équilibre dans les relations entre sous-traitants, entrepreneur et maître d'ouvrage, reste contraire à la liberté du travailleur de choisir son travail et à la garantie du droit au travail assurée par le Code congolais du travail, la Constitution congolaise ou la Déclaration universelle des droits de l'homme d'autant plus qu'en pratique le contrat de travail en sous-traitance est le plus souvent un contrat à durée déterminée et qu'une meilleure proposition venant des cocontractants de l'entreprise sous-traitante serait peut-être avantageuse. Il serait plus judicieux de laisser au travailleur la liberté de choisir son futur employeur et non de lui imposer une « quasi clause de non-concurrence » qui n'obéit pas, par ailleurs, aux prescriptions du Code du travail en la matière ${ }^{8}$. L'autorité nationale, provinciale ou locale compétente, chacune en ce qui la concerne, est chargée du contrôle des entreprises sous-traitantes. Les sanctions pourront aller des amendes à la fermeture d'entreprise.

Profitant de cette main tendue aux entrepreneurs congolais, le ministère des petites et moyennes entreprises a décidé de lancer, en septembre 2017, une campagne visant à répertorier, via un formulaire mis en ligne à partir du portail du ministère, les PME viables et à vulgariser la nouvelle loi sur les règles applicables à la sous-traitance dans le secteur privé. Celle-ci, pourrait favoriser la création d'emplois durables, l'éclosion d'une classe moyenne d'entrepreneurs locaux, réduire les inégalités et encourager l'innovation et la compétitivité d'après les initiateurs de cette opération. 